\title{
Analysis of the interfacial debonding behaviour of NSM CFRP laminates with cement-based adhesive using Digital Image Correlation technique
}

\author{
MohammadiFirouz, R. ${ }^{1}$, Matos, L.M.P ${ }^{1}$, Pereira, E.N.B. ${ }^{1}$, Barros, J.A.O. ${ }^{1}$ \\ ${ }^{1}$ ISISE, Institute for Sustainability and Innovation in Structural Engineering, Department of \\ Civil Engineering, University of Minho, Guimarães, Portugal \\ rezamfecivil.uminho.pt
}

\begin{abstract}
The superb performance of carbon fiber reinforced polymer (CFRP) composites as near surface mounted (NSM) reinforcement in strengthening solutions for structures is already well recognized. Due to their deficiencies in fire conditions, cement-based adhesives as an alternative to polymeric matrices are recently suggested as a solution in these systems. However, the interface between the CFRP laminate and cement-based adhesives should have good stress transferring capacity. Thus, it is of great importance the research on improving this interface to increase the bonding capacity of CFRP/cement-based adhesive system. For that purpose, pull-out tests were conducted to examine the interfacial debonding process of two types of CFRP laminates: conventional smooth surface laminates and sand surface treated laminates. Digital image correlation (DIC) technique was used to verify the potentiality of the proposed sand treating approach. Therefore, the interlocking mechanism of sand treated laminates with the developed cement-based adhesive is assessed and the results are compared to those with non-treated smooth surface laminates. Furthermore, the bond-slip behaviour from pull-out tests is compared to obtained data through the DIC technique. The results verified the effectiveness of sand treatment approach applied to NSM CFRP reinforcements. Moreover, the DIC technique has revealed capable of providing qualitative and quantitative information in this regard.
\end{abstract}

Keywords: FRP, NSM, Cement Adhesive, sand treatment, DIC.

\section{Introduction}

During the past decades, strengthening of concrete structures by means of Carbon Fibre Reinforced Polymers (CFRP) has been vastly investigated and is now a widely accept method to rehabilitate deficient or deteriorating structures. These materials are very appealing due to their high tensile capacity, lightweight, corrosion resistance and relatively ease of installation. Near Surface Mounted (NSM) technique is one of the most adopted approaches in the application of FRP-based strengthening to enhance structural 
performance. This approach consists in cutting grooves in the cover of reinforced concrete $(\mathrm{RC})$ element and embedding the CFRP strip or bars within an adhesive medium pre-introduced into the grooves. Some of the advantages of this methodology include the elimination of surface preparation, increased protection from environmental effects and vandalism acts, and preventing pre-mature debonding, compared to externally bonded reinforcement (EBR) technique [1]. In recent years, many researchers have proven the efficiency of such NSM technique in increasing flexural [2], shear [3], torsional [4], and punching [5] capacity of reinforced concrete (RC) elements.

In the NSM technique, the bonding capacity of the adhesive material plays an essential role in the performance of the rehabilitated element, and often constitutes a cut off factor in the expected structural performance [6]. Typically, epoxy-based materials are used to ensure the stress transferring mechanism between the CFRP and the concrete substrate. However, fire resistance of such materials is one major drawback due to their low glass transition temperature ( $\mathrm{Tg}$ ). When subjected to high temperatures, their bonding capacity is severely affected, which compromises the structural performance of the strengthening intervention. In an attempt of surpassing this limitation, some researchers suggested the use of cementitious-based materials as bonding agent between the CFRP and the concrete substrate [7-9]. In this research, a cement-based material is used as an adhesive for NSM CFRP strengthening technique.

Digital Image Correlation (DIC) is a computer image-based measurement technique that consists in monitoring the undergoing deformations of materials by tracking a regular grid of points on the surface of the specimen over subsequent digital images [10]. The captured images are divided in sets of pixels called "facets", which are tracked throughout the process by means of the greyscale values of the pixels that compose the facet. Thus, the uniqueness of each facet is of utmost importance since this will aid the algorithm to monitor the facet throughout the process [11]. Moreover, smaller facet sizes will lead to higher resolution in the obtained results. However, the computation time significantly increases and can result in the inability of the algorithm to correlate the facet position since there is a smaller number of "features", or in other words, the uniqueness of each facet decreases [12]. Some materials have enough features on the surface to allow the application of DIC technique, i.e. concrete or stone. In order to decrease the measurement error and ensure results over the entire imaged area, a stochastic speckle pattern is applied onto the surface of the specimen for granting the uniqueness of the facets. This methodology presents several advantages since it is a non-destructive/non-contact technique and allows the monitoring of the entire surface of interest, whereas more conventional approaches are restricted to a discrete number of points. Furthermore, in case of concrete structures, DIC is capable of detecting crack formation and propagation on a much early stage, eliminating the necessity of pausing the test to photograph and mark the specimen throughout the experimental study [13]. Several researchers have been exploring the potential of DIC technique to measure deflection and crack widths in concrete beams [14], the fatigue behaviour of strengthened RC beams [13], analysing the bond-slip behaviour of FRP to concrete elements [15, 16] and monitor crack patterns [17]. 
The current research is focused on the bond-slip response of CFRP laminates attached to the concrete substrate by cementitious-based adhesive. The interaction between the CFRP laminates and the adhesive was evaluated using the DIC technique.

\section{Experimental work}

The experimental program consists of pull-out tests of NSM CFRP strips, in order to investigate the bond stress-slip behaviour between the cement-based adhesive and laminates with smooth and sand treated surfaces.

The experimental study consists of two series of pull-out tests, considering two types of CFRP laminates, namely, untreated (UT) smooth surface laminates and fine sand treated (FS) laminates. Fine sand with the particle size in the range of 0.6 to $0.85 \mathrm{~mm}$ was used to cover these surfaces with $\mathrm{S} \& \mathrm{P}^{\circledR} 55$ epoxy resin, as the bonding agent. Figure 1 shows a typical FS and UT laminate.

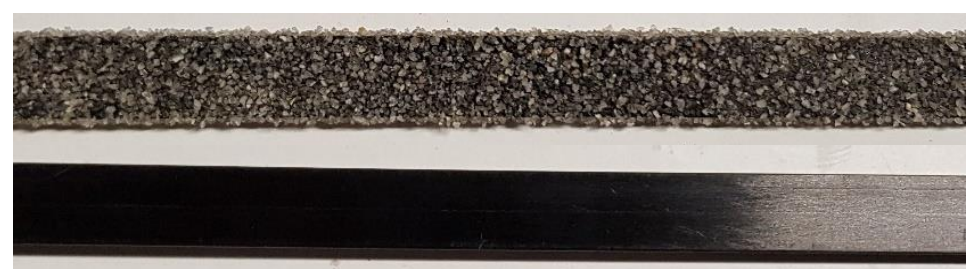

Figure 1 - Sand treated (top) and smooth (bottom) surface CFRP laminates

\subsection{Specimen and mixture description}

The specimens consist of 3 normal strength concrete blocks (class of C20/25 according to the Eurocode 2 ) with $200 \times 200 \times 100 \mathrm{~mm}$ dimensions. On each prism, two grooves were cut to introduce CFRP laminates. In Figure 2a schematic representation of the specimens is presented. In order to perform NSM strengthening, $\mathrm{S} \& \mathrm{P}^{\circledR} \mathrm{CFRP}$ laminates supplied by Clever Reinforcement with a cross section of $1.4 \times 10 \mathrm{~mm}^{2}$ and average tensile strength and modulus of elasticity of $1909 \mathrm{MPa}$ and $171 \mathrm{GPa}$, respectively, were used in this work. The laminates are inserted and centred into the grooves that were pre-filled with cement adhesive (Figure 2).

In order to capture the evolution of the sliding between laminate and surrounding adhesive, the top surface of the laminate was cleared from adhesive so that a better view of the laminate's bonding zone can be obtained. Hence, only the lateral and bottom faces of the CFRP laminates are embedded in the adhesive material. Nonetheless, bonding performance is not significantly affected since the top face only corresponds to $6.5 \%$ of the total bonding area and has no attachments to the concrete substrate.

A schematic representation as well as photographs of the specimens are presented in Error! Reference source not found. 
The description of the mixture composition used for cement-based adhesive, herein designated as CBA, is presented in Table 1.

Table 1. Mixture and properties of cement-based adhesive

\begin{tabular}{cccccccc}
\hline $\begin{array}{c}\text { Cement } \\
\text { type }\end{array}$ & $\begin{array}{c}\text { Silica } \\
\text { fume }\end{array}$ & $\begin{array}{c}\text { Water/ } \\
\text { Binder }\end{array}$ & $\begin{array}{c}\text { Super } \\
\text { plasti- } \\
\text { cizer }\end{array}$ & $\begin{array}{c}\text { Shrinkage } \\
\text { reducing } \\
\text { agent }\end{array}$ & $\begin{array}{c}\text { Fine } \\
\text { sand/Binder }\end{array}$ & $\begin{array}{c}\text { Compressive } \\
\text { strength }\end{array}$ & $\begin{array}{c}\text { Modulus of } \\
\text { elasticity }\end{array}$ \\
\hline CEM I & $\begin{array}{c}15 \% \text { of } \\
\text { binder }\end{array}$ & $20 \%$ & $\begin{array}{c}2 \% \text { of } \\
\text { binder }\end{array}$ & $\begin{array}{c}2 \% \text { of } \\
\text { binder }\end{array}$ & $50 \%$ (mass) & $78.6 \mathrm{MPa}$ & $29.6 \mathrm{GPa}$ \\
$\begin{array}{c}52.5 \mathrm{R} \\
\text { (grey) }\end{array}$ & \begin{tabular}{c} 
(vol) \\
\hline
\end{tabular} & & & & & \\
\hline
\end{tabular}

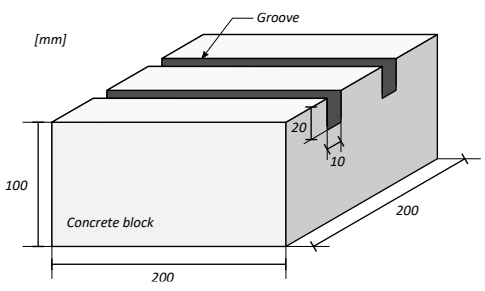

a)

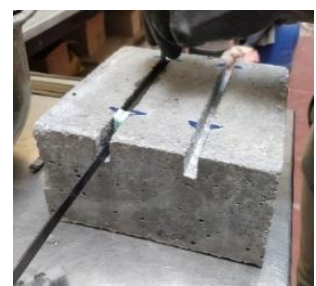

c)

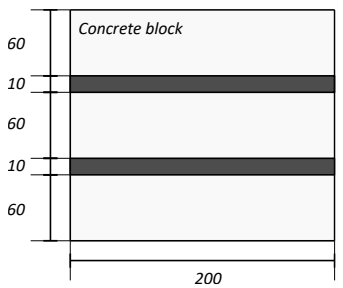

b)

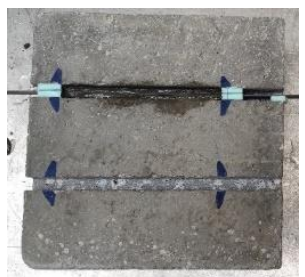

d)

Figure 2. Schematic representation of the specimen in a) perspective and b) plan view; c) placement of CFRP laminate inside the groove, and d) Strengthened prism (all dimensions are in $\mathrm{mm}$ )

\section{$2.2 \quad$ Test setup}

A pull-out test configuration is presented in Figure 2. Linear variable differential transformers (LVDT) were used to record both loaded-end and free-end slip of CFRP laminates. In addition, a DIC system was applied to monitor the displacement and strain fields on the surface of the specimens. The DIC and LVDT results are compared as well as the performance of the two types of CFRP laminates, when embedded in cementbased adhesives. The pull-out tests were conducted using a displacement control protocol by imposing a displacement rate of $2 \mu \mathrm{m} / \mathrm{s}$ and the force was monitored by means of a $50 \mathrm{kN}$ load cell. 
The Q-400 3D DIC system from Dantec Dynamics was used in this study. This system is composed by 2 cameras with $2.5 \mathrm{MP}$ resolution, two light lamps, a support frame and a tripod. The system was connected to a laptop computer and the image capturing procedure was controlled in the ISTRA 4D software. The image acquisition rate was set to $1 \mathrm{~Hz}$ continuously throughout the loading procedure. The setup configuration of the DIC system is depicted in Figure 4.

In order to apply the DIC technique, a speckle pattern was applied onto the surface of the specimens and inside the NSM grooves. The pattern was applied in two phases, firstly the surface of the specimen was sprayed with a thin layer of white, and subsequently the region of interest was sprayed with black ink in a dynamic manner in order to create a random speckle pattern. The obtained speckle pattern within the NSM groove is presented in Figure 5.

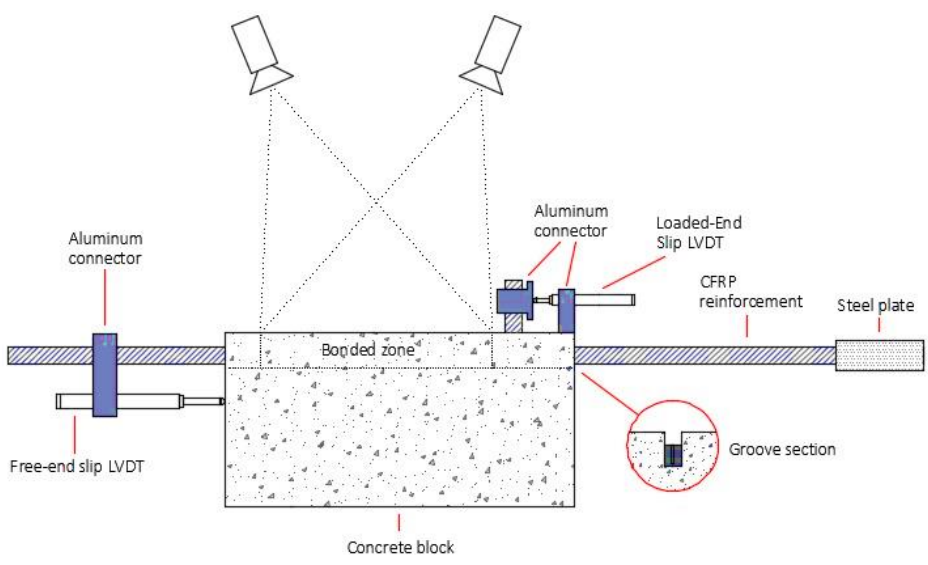

Figure 3. Schematic representation of the pull-out test setup schematic of the LVDT placement and DIC system cameras 

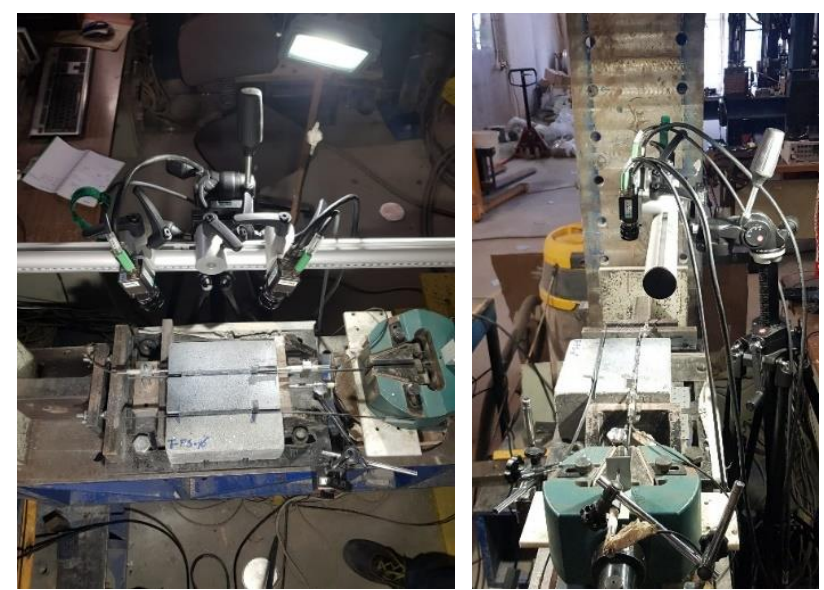

Figure 4. Setup configuration of the DIC Q-400 system

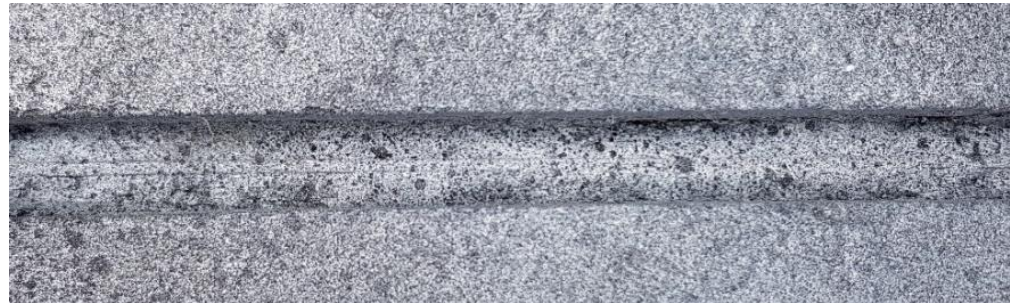

a)

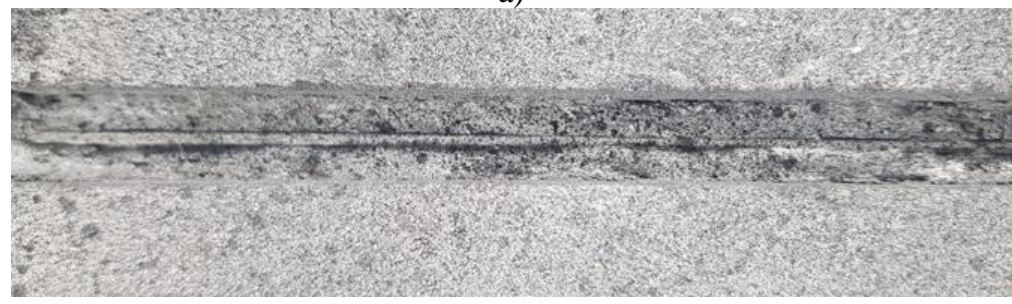

b)

Figure 5. Speckle pattern applied onto the region of interest; a) sand treated NSM CFRP, b) un-treated NSM CFRP

\section{Results and discussion}

In total, 6 samples were prepared, NSM strengthened using cement-based adhesive, and tested. Three of them were strengthened using un-treated laminates, while in other three with sand treated CFRP reinforcements were used. The summary of the obtained results from direct pull-out tests is presented in Table 2. It is verified the high capability of sand treatment of CFRP's surfaces to increase the maximum pull-out force, as previous researches also reported $[9,18]$. The FS-CA samples could carry a pull-out force, 
up to 5.38 MPa of average bonding stress, while this value was 0.66 MPa for NT-CA samples. The average maximum pull-out force for samples strengthened with sand treated laminates (FS-CA) was $12.91 \mathrm{KN}$, which was about 7 times more than NT-CA samples with average maximum pull-out force of $1.77 \mathrm{KN}$. The coefficient of variation $(\mathrm{COV})$ for these values were $18.7 \%$ and $5.7 \%$, respectively.

Table 2. Pull-out test results

\begin{tabular}{ccccc}
\hline Label & $\begin{array}{c}\text { Maximum } \\
\text { pull-out force } \\
{[\mathrm{KN}]}\end{array}$ & $\begin{array}{c}\text { Load-end slip at } \\
\text { max force } \\
{[\mathbf{m m}]}\end{array}$ & $\begin{array}{c}\text { Free-end slip at } \\
\text { max force } \\
{[\mathbf{m m}]}\end{array}$ & $\begin{array}{c}\text { Avg. bond } \\
\text { strength } \\
{[\mathrm{MPa}]}\end{array}$ \\
\hline \multirow{3}{*}{ P-NT-CA } & 1.87 & 0.054 & 0.003 & 0.66 \\
& $1.75^{*}$ & 0.107 & 0.006 & 0.61 \\
& 1.67 & 0.046 & 0.009 & 0.59 \\
\hline \multirow{2}{*}{ P-FS-CA } & 15.32 & 0.488 & 0.043 & 5.38 \\
& $13.52^{*}$ & 0.451 & 0.053 & 4.74 \\
\hline
\end{tabular}

(P) Pull-out test, (NT) no treatment, (FS) fine sand treatment, (CA) cement adhesive (*) DIC

Results showed the effectiveness of the sand treating approach in terms of improving the bond between CFRP reinforcements and cement-based adhesive. The adopted technique increased the roughness of the CFRP laminate surfaces, and consequently the interlock resisting mechanisms between this type of laminate and used adhesive. In order to study this mechanism, DIC technique was used to observe the interaction between laminate and adhesive with the evolution of pull-out force during the test.

Figure 6 shows the interaction in the between un-treated and sand treated CFRP laminates and cement-based adhesive in different stages of maximum pull-out force in terms of strain. The negative value is due to the direction of $\mathrm{X}$ coordinate and the positive values are considered as error in DIC evaluation. The hollow spaces, visible as white colour are zones in which the software could not follow the facets due to the debilities in stochastic pattern or due to large displacements undermining the face tracking algorithm. The results are showing the exposed face of bonding zone in the samples as illustrated in Figure 5. The interaction between the two types of CFRP reinforcement and cement-based adhesive is clear in the images. The aforementioned interlocking mechanism between the laminate's sand treatment layer and adhesive is evident with cracks, forming as the bonding stress on this interface increases. However, this is not observed for the sample strengthened with untreated CFRP laminate, where much less interaction took place up to the maximum bonding capacity of the strengthened system. 


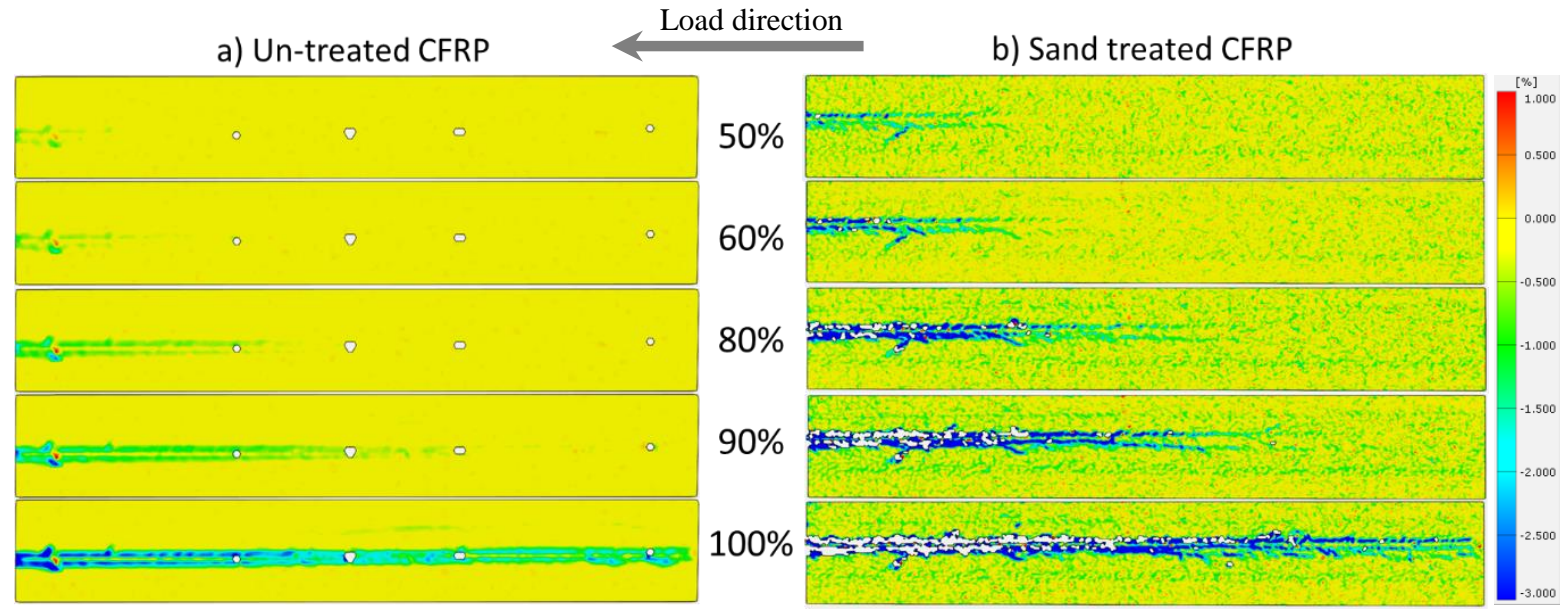

Figure 6. The strain profile for (a) un-treated and (b) sand treated CFRP laminates and cement-based adhesive in different stages of maximum pull-out force

In Figure 7, pull-out force vs. loaded-end and free-end slip curves from the tests are shown for a) untreated, and b) sand treated NSM CFRP reinforcements. In this figure, the obtained slip curves from DIC technique are also demonstrated; however, these values were shown only up to the peak load. This is due to the brittle behaviour of the cement-based adhesive, which caused a sudden pull-out force drop and an abrupt displacement in the laminate that caused the inability of the DIC algorithm to follow the facets. The curves obtained from DIC are in relatively good agreement with the experimental data for the ascending branch of pull-out force/slip relationship. However, in case of the sand treated NSM CFRP laminates, there is a difference between the experimental data and DIC results for pull-out force/free-end slip curve.

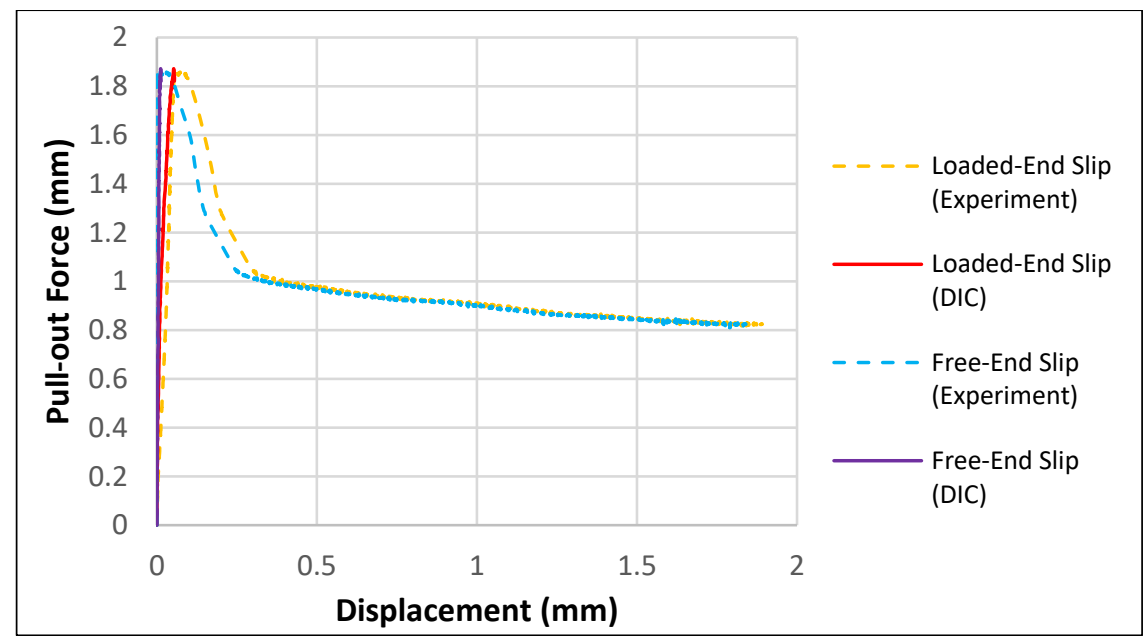

a) 


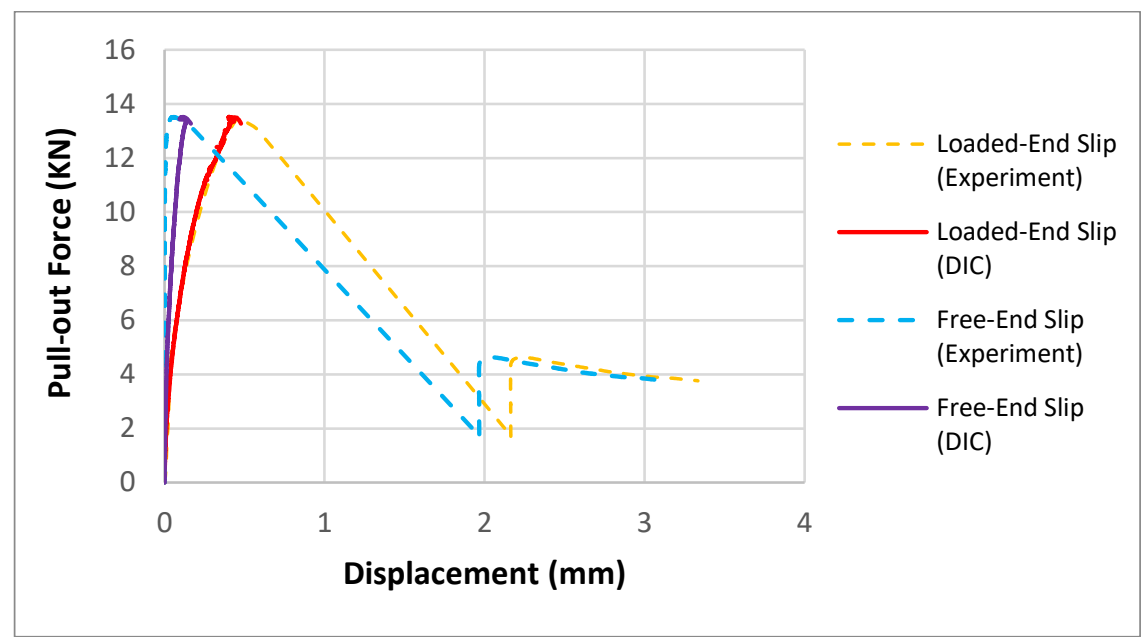

b)

Figure 7. Pull-out force versus slip curve for a) un-treated NSM CFRP, b) sand treated NSM CFRP reinforcements

\section{Conclusion}

In the present work a preliminary analysis of bonding performance of NSM CFRP with cement-based adhesive by using digital image correlation technique was performed. Two different types of CFRP reinforcements were used in the strengthening process: (1) plain untreated, and (2) sand treated CFRP reinforcements. The laminates were installed on the surface, and the bonding region was monitored during the test and later analysed using DIC technique.

Using cement-based adhesive, the average pull-out force for untreated and sand treated NSM CFRP strengthened samples was $1.77(\mathrm{CoV}=6 \%)$ and $12.91(\mathrm{CoV}=19 \%)$, respectively. Hence, the adopted treatment strategy was able to increase the average maximum pull-out force about 7 times, compared to those strengthened with untreated NSM CFRP reinforcements.

It is also demonstrated the resisting forces between CFRP reinforcement and cement-based adhesive along the bonding length throughout the increasing evolution of pull-out force. The comparison between the samples with two different CFRP reinforcements, the crack growth on the interface of sand treated CFRP/adhesive shows its better performance, compared to un-treated laminate. The DIC analysis showed the effectiveness of interlocking mechanism on the interface of CFRP laminate/adhesive, produced by the sand layer.

Based on the results obtained from monotonic pull-out tests, the extracted data from DIC analysis for samples with untreated and sand treated CFRP laminates were plotted 
in load/slip graph. DIC analysis showed a relevant agreement with experimental data for the ascending branch of pull-out force/slip. However, it could only capture the behaviour until the peak load due to brittle failure of the samples and consequent abrupt slip gradient that made it impossible to follow the facets during the image analysis. Nonetheless, the DIC approach provides the possibility to observe the crack formation throughout the bond zone prior to the sudden pull-out of the FS treated laminate.

\section{Acknowledgements}

The Authors acknowledge the support provided by FCT through the PTDC/ECMEST/1882/2014 FIRECOMPOSITE project. The collaboration of Sika and Clever reinforcement Iberica is also acknowledged.

References

1. De Lorenzis, L. and J.G. Teng, Near-surface mounted FRP reinforcement: An emerging technique for strengthening structures. Composites Part B: Engineering, 2007. 38(2): p. 119-143.

2. Dalfré, G.M. and J.A.O. Barros, NSM technique to increase the load carrying capacity of continuous RC slabs. Engineering Structures, 2013. 56: p. 137153.

3. Dias, S.J.E. and J.A.O. Barros, NSM shear strengthening technique with CFRP laminates applied in high T cross section RC beams. Composites Part B: Engineering, 2017. 114: p. 256-267.

4. Gowda, C.C., J.A.O. Barros, and M. Guadagnini, Experimental study of torsional strengthening on thin walled tubular reinforced concrete structures using NSM-CFRP laminates. Composite Structures, 2019. 208: p. 585-599.

5. Barros, J.A.O., et al., Simultaneous flexural and punching strengthening of $R C$ slabs according to a new hybrid technique using U-shape CFRP laminates. Composite Structures, 2017. 159: p. 600-614.

6. Lorenzis, L.D. and A. Nanni, Bond between Near-Surface Mounted FiberReinforced Polymer Rods and Concrete in Structural Strengthening. ACI Structural Journal, 2002. 99(2).

7. Hashemi, S. and R. Al-Mahaidi, Investigation of bond strength and flexural behaviour of FRP-strengthened reinforced concrete beams using cementbased adhesives. Australian Journal of Structural Engineering, 2010. 11(2): p. 129-139.

8. Täljsten, B. and T. Blanksvärd, Mineral-based bonding of carbon FRP to strengthen concrete structures. Journal of Composites for Construction, 2007. 11(2): p. 120-128.

9. Firouz, R.M., E.N.B. Pereira, and J.A.O. Barros. Cementitious adhesives for NSM carbon laminate strengthening system with treated surfaces. in IABSE 
Symposium, Guimaraes 2019: Towards a Resilient Built Environment Risk and Asset Management - Report. 2019.

10. Sutton, M.A., et al., Advances in two-dimensional and three-dimensional computer vision, in Photomechanics, P.K. Rastogi, Editor. 2000, Springer Berlin Heidelberg: Berlin, Heidelberg. p. 323-372.

11. Crammond, G., S.W. Boyd, and J.M. Dulieu-Barton, Speckle pattern quality assessment for digital image correlation. Optics and Lasers in Engineering, 2013. 51(12): p. 1368-1378.

12. Triconnet, K., et al., Parameter choice for optimized digital image correlation. Optics and Lasers in Engineering, 2009. 47(6): p. 728-737.

13. Mahal, M., et al., Using digital image correlation to evaluate fatigue behavior of strengthened reinforced concrete beams. Engineering Structures, 2015. 105: p. 277-288.

14. Destrebecq, J.-F., E. Toussaint, and E. Ferrier, Analysis of Cracks and Deformations in a Full Scale Reinforced Concrete Beam Using a Digital Image Correlation Technique. Experimental Mechanics, 2011. 51(6): p. 879890.

15. Zhu, H., et al., Digital image correlation measurement of the bond-slip relationship between fiber-reinforced polymer sheets and concrete substrate. Journal of Reinforced Plastics and Composites, 2014. 33(17): p. 1590-1603.

16. Corr, D., et al., Digital image correlation analysis of interfacial debonding properties and fracture behavior in concrete. Engineering Fracture Mechanics, 2007. 74(1-2): p. 109-121.

17. Yu, K.-Q., et al., Development of ultra-high performance engineered cementitious composites using polyethylene (PE) fibers. Construction and Building Materials, 2018. 158: p. 217-227.

18. Barros, R.M.E.N.B.P.J.A.O., Bond performance of NSM - CFRP laminates using different surface treatments and cementitious adhesives, in Fiber Reinforced Polymer for Reinforced Concrete Structures (FRPRCS) 14. 2019: Belfast, Northern Ireland. p. 1-4. 